\title{
ERS statement: interventional bronchoscopy in children
}

\author{
Ernst Eber ${ }^{1}$, Juan L. Antón-Pacheco ${ }^{2}$, Jacques de Blic ${ }^{3}$, Iolo Doull ${ }^{4}$, Al Faro ${ }^{5}$, \\ Raffaella Nenna ${ }^{6}$, Thomas Nicolai ${ }^{7}$, Petr Pohunek ${ }^{8}$, Kostas N. Priftis ${ }^{9}$, \\ Paola Serio ${ }^{10}$, Courtney Coleman ${ }^{11}$, Sarah Masefield ${ }^{11}$, Thomy Tonia ${ }^{12}$ and \\ Fabio Midulla ${ }^{6}$
}

\begin{abstract}
Affiliations: 'Division of Paediatric Pulmonology and Allergology, Dept of Paediatrics and Adolescent Medicine, Medical University of Graz, Graz, Austria. ${ }^{2}$ Paediatric Airway Unit and Paediatric Surgery Division, Hospital Universitario 12 de Octubre, Universidad Complutense de Madrid, Madrid, Spain. ${ }^{3}$ Assistance Publique Hôpitaux de Paris, Hôpital Universitaire Necker-Enfants Malades, Paediatric Pulmonary Dept, Université Paris Descartes, Paris, France. ${ }^{4}$ Dept of Paediatric Respiratory Medicine, Children's Hospital for Wales, Cardiff, UK. ${ }^{5}$ Cystic Fibrosis Foundation, Bethesda, MD, USA. "Dept of Paediatrics, "Sapienza" University of Rome, Rome, Italy. ${ }^{7}$ University Children's Hospital, Ludwig Maximilians University Munich, Munich, Germany. ${ }^{8}$ Paediatric Dept, 2nd Faculty of Medicine, Charles University and Motol University Hospital, Prague, Czech Republic. ${ }^{9} 3 \mathrm{rd}$ Dept of Paediatrics, University General Hospital Attikon, National and Kapodistrian University of Athens, Athens, Greece. ${ }^{10}$ Dept of Paediatric Anaesthesia and Intensive Care, Meyer Children Hospital, Respiratory Endoscopy Unit, Florence, Italy. ${ }^{11}$ European Lung Foundation, Sheffield, UK. ${ }^{12}$ Institute of Social and Preventive Medicine, University of Bern, Bern, Switzerland.
\end{abstract}

Correspondence: Fabio Midulla, Dept of Paediatrics and Infantile Neuropsychiatry, Sapienza University of Rome, Viale Regina Elena 324, 00161 Rome, Italy.

E-mail: midulladuniroma1.it

@ERSpublications

Interventional bronchoscopy in children: evidence at present, clinical practice and areas for further investigation http://ow.ly/Z7Rv30fuPV6

Cite this article as: Eber E, Antón-Pacheco JL, de Blic J, et al. ERS statement: interventional bronchoscopy in children. Eur Respir J 2017; 50: 1700901 [https://doi.org/10.1183/13993003.00901-2017].

ABSTRACT Paediatric airway endoscopy is accepted as a diagnostic and therapeutic procedure, with an expanding number of indications and applications in children. The aim of this European Respiratory Society task force was to produce a statement on interventional bronchoscopy in children, describing the evidence available at present and current clinical practice, and identifying areas deserving further investigation. The multidisciplinary task force panel performed a systematic review of the literature, focusing on whole lung lavage, transbronchial and endobronchial biopsy, transbronchial needle aspiration with endobronchial ultrasound, foreign body extraction, balloon dilation and occlusion, laser-assisted procedures, usage of airway stents, microdebriders, cryotherapy, endoscopic intubation, application of drugs and other liquids, and caregiver perspectives. There is a scarcity of published evidence in this field, and in many cases the task force had to resort to the collective clinical experience of the committee to develop this statement. The highlighted gaps in knowledge underline the need for further research and serve as a call to paediatric bronchoscopists to work together in multicentre collaborations, for the benefit of children with airway disorders.

This document was endorsed by the ERS Science Council and Executive Committee in September 2017.

Received: May 022017 | Accepted after revision: Aug 082017

Support statement: This task force was funded by the European Respiratory Society (TF-2015-09). Funding information for this article has been deposited with the Crossref Funder Registry.

Conflict of interest: C. Coleman and S. Masefield are employees of the European Lung Foundation. T. Tonia acts as a methodologist for the European Respiratory Society.

Copyright @ERS 2017 


\section{Introduction}

For decades, interventional bronchoscopy in children was limited to foreign body extraction [1]. In 1978, the first report on diagnostic flexible bronchoscopy in children was published [2]. Subsequently, bronchoscopy has become an increasingly important tool in children with acute and chronic lung diseases. In 2003, a European Respiratory Society (ERS) task force published their results on flexible endoscopy of paediatric airways, concluding that it is a safe procedure provided the child is properly prepared and the procedure is performed by skilled and trained personnel [3]. In parallel with adult bronchoscopy, paediatric airway endoscopy has evolved from a primarily diagnostic procedure to include therapeutic (i.e. interventional) bronchoscopy, facilitated by the development of new and smaller instruments and devices. Today, advanced therapeutic techniques such as laser treatment, balloon dilation and stent placement are used in children in specialised centres, with an expanding number of applications and indications. A recent American Thoracic Society task force has published technical standards on flexible airway endoscopy in children [4]. The aim of this ERS task force was to produce a statement based on a systematic review of the literature on interventional bronchoscopy in children. This statement describes the evidence at present and current clinical practice, and identifies areas for future research, but does not provide recommendations for clinical practice.

\section{Methods}

The task force panel consisted of a group of clinicians with internationally recognised expertise in interventional bronchoscopy in children; a member of the early career committee of the ERS; and representatives of the European Lung Foundation (ELF). An ERS methodologist gave feedback on the research strategy and evidence synthesis and overlooked the task force process.

Panel members disclosed potential conflicts of interest according to ERS policies at the start of the task force and prior to the publication of this manuscript. The task force was initiated in September 2015 and held three face-to-face meetings, several telephone conferences and regular exchanges by e-mail. The task force members agreed on the topics that would be the focus of their work, based on clinical importance. It was decided to restrict the focus of this task force to the tracheobronchial tree, excluding the larynx, as this part of the airway is usually dealt with by ear, nose and throat specialists. Each topic of interest was assigned to a subgroup of experts, and each subgroup was led by one colleague.

The subgroups were responsible for performing systematic literature searches using the MEDLINE (accessed via PubMed) and Scopus databases. They first looked for systematic literature reviews, then randomised controlled trials (RCTs); if such studies were not available, they searched for observational studies, published between 1996 and 2015 in English, regardless of impact factor. In cases of limited paediatric evidence, position statements from the adult literature were consulted. For the literature searches, the main keywords child ${ }^{*}$ or paediatric or pediatric, and bronchoscopy were used in addition to other relevant specific keywords. The ELF representatives conducted systematic searches of published and grey literature (online parent discussion forums) to identify parent and caregiver concerns and experiences. Records identified through database searching were complemented with additional studies identified by task force members. Duplicates were removed and titles and abstracts screened; the full text was then reviewed in potentially eligible articles.

Selected studies formed the basis of a first draft for each section, which was prepared by the subgroup leaders. The drafts were discussed during subsequent meetings and telephone conferences. Where applicable, the evidence was complemented with descriptions of current practice, based on the experience of the task force members. Thus, this statement describes the evidence at present and current clinical practice, but does not provide recommendations for clinical practice.

An additional final literature search was conducted in December 2016, in order to identify any studies published since the original search.

Advanced drafts were then submitted to the task force chairs who integrated each of the subsections into a uniform manuscript. The final version of this manuscript was reviewed and approved by all task force members prior to submission.

\section{Results}

Bronchoalveolar lavage (whole-lung lavage)

Bronchoalveolar lavage (BAL) is the most frequent procedure performed during flexible bronchoscopy, for diagnostic or therapeutic reasons. Technique and indications of diagnostic BAL have been the subject of recent international recommendations [4-6]. Here we focus on whole-lung lavage (WLL) as a therapeutic option. 


\section{Overview of the evidence and current practice}

Specific search terms were whole lung lavage, interstitial pneumonitis and alveolar proteinosis. 35 articles were selected; there were no meta-analyses or RCTs, but only case series $(n=3)$ and case reports available.

WLL is performed under general anaesthesia and, usually, muscle relaxation, with monitoring including ECG, blood pressure, pulse oximetry and capnography. In children aged $\geqslant 8$ years, the technique is the same as in adults, using a double-lumen endotracheal tube (ETT) [7]. The smallest double-lumen ETT is 26 French $(\sim 8.7 \mathrm{~mm})$. In infants and small children, different techniques have been proposed [8]: WLL through an elongated cuffed ETT [7] or through a balloon catheter [8,9]; use of two ETTs: a bronchial tube for the lavage and a tracheal tube for ventilation $[8,10,11]$; WLL via the channel of a flexible bronchoscope with an external diameter of $2.8,3.5$ or $4.9 \mathrm{~mm}$, according to the age of the patient, which allows direct visualisation and more selective lobar lavages (two techniques have been used, one with the bronchoscope being pushed down alongside a narrow ETT, or with it inserted in a large ETT [12-14]); and in severely ill children, WLL has been performed under extracorporeal membrane oxygenation [15] or liquid ventilation using polyurethane perflubron [16].

Only one lung is washed during each session, using prewarmed normal saline. When using an elongated ETT, lavage is performed using passive gravity. With the other techniques, lavage is performed using a syringe with aliquots of $20-120 \mathrm{~mL}$. The lavage is continued until the effluent is satisfactorily clear. The recovered fluid can be collected via a two-way stopcock into bottles to assess turbidity. Total volume instilled is $\sim 200-300 \mathrm{~mL} \cdot \mathrm{kg}^{-1}[9,10,12]$.

WLL is frequently associated with episodes of hypoxaemia and hypercapnia. In one study analysing 64 WLLs [9], oxygen saturation values $<70 \%$ occurred in the sickest patients and carbion dioxide tension $\left(\mathrm{PCO}_{2}\right)$ values increased up to $80 \mathrm{mmHg}(10.67 \mathrm{kPa})$.

WLLs are performed in disease states associated with alveolar filling by abnormal material, with the most frequent being pulmonary alveolar proteinosis [11, 17-25]. In addition, WLLs have been used in children with metabolic disorders such as lysinuric protein intolerance [26, 27], Niemann-Pick disease [28-30] or lipoid pneumonia [31-37].

\section{Conclusions}

The role of WLL in children with alveolar filling disorders is well established.

\section{BOX 1}

Some members of the task force perform WLL:

at institutions with highly experienced bronchoscopy and anaesthesiology teams in children with alveolar filling disorders

Gaps in knowledge/recommendations for future research/training

Studies to work out the best technique for WLL

Studies to assess the potential side-effects of WLL on alveolar epithelium

\section{Transbronchial and endobronchial biopsy}

Overview of the evidence and current practice

Specific search terms were transbronchial biopsy, endobronchial biopsy, brush biopsy and ciliary biopsy. The search yielded 116 articles, including 20 review papers, 22 prospective and 22 retrospective studies, 30 case-control studies and 22 case series and case reports. Of those, 14 relevant articles were selected.

Transbronchial biopsy (TBB) in children is standard practice to monitor the lung allograft after transplantation, either as a surveillance or clinically indicated procedure. [38, 39]. The technique has been described previously $[4,39]$. One study reported that $25 \%$ of TBBs performed in lung transplant recipients were undertaken for surveillance, $38 \%$ for follow-up of acute rejection and $37 \%$ for respiratory symptoms [40]. A treatable grade of acute rejection was found in $24 \%$ of the surveillance procedures. Additionally, this study compared findings by whether TBB was performed with adult biopsy forceps or paediatric biopsy forceps. Only $5 \%$ of the surveillance TBBs performed with paediatric forceps demonstrated acute rejection compared to $29 \%$ of the biopsies performed with adult forceps; the confounder being that the paediatric forceps were used in the younger patients, where the incidence of acute rejection is lower [41]. There was no difference in rates of acute rejection between the different sized forceps when TBB was clinically indicated. Another study of 95 surveillance TBBs in children (aged 4.9-17.3 years at time of transplant) found treatable acute rejection in $4 \%$ of asymptomatic children and in $12 \%$ of those with symptoms [42]. 11 (12\%) 
of the procedures recovered an inadequate amount of tissue to grade for rejection. Complications included one pneumothorax, one episode of moderate bleeding and one aspiration event (complication rate 3.2\%).

Beside lung transplantation, there is a dearth of data for TBB in paediatric lung disease. One study described the findings of TBB in 38 children ranging in age from 2 weeks to 18 years [40]. Dividing outcomes based on the size of the biopsy forceps, the $1.2-\mathrm{mm}$ paediatric forceps yielded an adequate tissue sample in $14(88 \%)$ of the 16 nontransplant patients compared to adequate sampling in $20(91 \%)$ of the 22 patients biopsied using the 2.0 - $\mathrm{mm}$ adult forceps. Despite an adequate sample size, the diagnostic yield was $50 \%$ for the paediatric forceps and $64 \%$ for the adult forceps. In five cases there was a subsequent open lung biopsy or explant, and in three of these cases TBB findings were confirmed without additional diagnostic findings. Pathologic findings included interstitial pneumonitis, bronchiolitis obliterans, lymphoma, eosinophilic pneumonia, sarcoidosis, hypersensitivity pneumonia, asthma, infections and aspiration. The procedure was well tolerated, but the complication rate was higher in the nontransplant $(8 \%)$ compared to the lung transplant $(<2 \%)$ group. However, all complications occurred in those children biopsied with the adult forceps and these included pneumothoraces and excessive bleeding. Two of the three pneumothoraces in the nontransplant group occurred in patients with cystic fibrosis.

An earlier study directly compared TBB to video assisted thoracoscopic surgery (VATS) and open lung biopsy (OLB) in immunocompetent children (age 1 month to 18 years) with interstitial lung disease (ILD). In this study, a specific diagnosis could be made $50 \%$ of the time with TBB, compared to $60 \%$ with VATS and 53\% with OLB [43]. The majority of the nondiagnostic procedures were performed in children aged $<2$ years. The only complication reported in the six children who underwent TBB was minor bleeding.

Beside these studies there are only paediatric case reports or series that contain mostly adult patients [4450]; no major complications were reported. TBB was not helpful in making a diagnosis of pulmonary cryptococcosis [51]. However, despite the data from two previous studies [40, 43], a recent algorithm proposed by the chILD-European Union Collaboration recommends against TBB, as the consensus opinion was that samples obtained via TBB are too small to diagnose most ILDs in children [52].

Endobronchial biopsies in children have been performed for both clinical and research indications in multiple disease states including asthma, cystic fibrosis, chronic cough and recurrent pneumonia [53-55].

\section{Conclusions}

The limited data in the literature suggest that TBB, in the hands of experienced bronchoscopists, can provide adequate tissue sampling and has a diagnostic yield of $\sim 50 \%$, which compares to a diagnostic yield of $50-80 \%$ for OLB or VATS, depending on the underlying diagnosis. Generally, TBB is well tolerated and leads to more rapid postprocedure recovery than either VATS or OLB. The risks associated with TBB may outweigh the benefits in children with hyperinflation, severe hypoxaemia, uncorrectable coagulopathies, cystic fibrosis and children on positive pressure ventilation.

\section{BOX 2}

All members of the task force perform TBB:

at institutions with bronchoscopy teams experienced in performing TBB and pathologists familiar with reviewing histology from TBB

in children following lung transplantation

Some members of the task force perform TBB:

in children with diffuse lung disease whose clinical state allows for the procedure to be performed safely in children with suspected interstitial lung disease, bronchiolitis obliterans, sarcoidosis, lymphoma and aspiration

\section{Gaps in knowledge/recommendations for future research/training}

Studies to assess the efficacy of TBB in children with ILD

Studies to assess the efficacy of TBB in children with nodular lung disease

Studies to assess whether newer techniques, such as transbronchial cryobiopsy or endobronchial ultrasound guided biopsy, are feasible or safe in children and whether they might provide greater diagnostic yield than TBB alone

\section{Transbronchial needle aspiration with endobronchial ultrasound}

Overview of the evidence and current practice

Specific search terms were endobronchial ultrasound, EBUS, transbronchial needle aspiration, and TBNA. The search yielded 57 articles, of which 35 were selected. 
Transbronchial needle aspiration (TBNA) with or without endobronchial ultrasound (EBUS) is primarily performed in adults for identification of lung cancers [56]. Conventional TBNA allows for sampling of mediastinal and hilar lymph nodes via a flexible bronchoscope, decreasing the need for more invasive techniques. Using a standard lymph node map and endobronchial landmarks, experienced operators blindly sample lymph nodes adjacent to the main airways [57]. Inadvertent puncture of vascular structures is a potential risk, although rarely reported. Conventional TBNA has been used successfully in the diagnosis of isolated intrathoracic tuberculous lymphadenopathy in symptomatic children aged $\geqslant 9$ months at high risk of tuberculosis $[58,59]$. Due to their size, younger children may only be suitable for subcarinal sampling, with a diagnostic yield of $\sim 50 \%$ [59]. Older children (aged $\geqslant 12$ years) may be amenable to right paratracheal, bronchial or hilar node sampling, thereby increasing the diagnostic yield to $>80 \%$ [58].

In contrast, EBUS TBNA allows real-time identification of the puncture site. Two types of EBUS are used in clinical practice. Radial probe EBUS is suitable for localisation and sampling of peripheral lesions such as pulmonary nodules. A $1.2-\mathrm{mm}$ diameter EBUS probe with a $1.7-\mathrm{mm}$ outer plastic guide sheath is passed through the working channel of the bronchoscope. Ideally, under fluoroscopic guidance, the bronchoscope is guided to the lung segment of interest. The EBUS is advanced sequentially into subsegments until the pathological area is identified. The EBUS is withdrawn, leaving the sheath in place, through which the biopsy forceps or brush is then passed and samples taken [60]. Currently, a $4.0-\mathrm{mm}$ bronchoscope is the smallest suitable for radial probe EBUS. Primarily used to identify lung cancer, it has been used to identify other causes of peripheral lung nodules, including mycobacterial infection. A meta-analysis of selected patients in centres of excellence reported a diagnostic yield of $70 \%$; complications are rare, with a pneumothorax rate of $1.5 \%$ [60]. In children, EBUS has been used to diagnose vascular malformations affecting the airway [61], but there are no reports of radial probe EBUS for peripheral lung lesions.

Linear (or convex) probe EBUS is performed using a dedicated bronchoscope (6.9-7.4 mm) with a linear array ultrasound transducer built into the tip (puncturescope). A disposable saline-filled balloon can be added to the tip to improve image quality. Lymph nodes of interest are identified by the puncturescope, and a flexible 21-gague or 22-gague needle is passed through the 2-mm instrument channel and then thrust 1520 times within the lymph node under real-time ultrasound visualisation. Lymph node contents can be aspirated by suction with a syringe [62]. After withdrawal a stylet is inserted through the needle to evacuate residual tissue. For diagnosis of lung cancer, the procedure is repeated a minimum of three times, but additional sampling may be required for microbiological diagnoses. Rapid on-site evaluation of tissue samples can be helpful to improve diagnostic yield, decrease the number of needle passes and reduce the need for additional diagnostic procedures [56]. In adults, linear probe EBUS TBNA is the investigation of choice for mediastinal or hilar lesions to identify lung cancer [63] and sarcoidosis [56], and may be helpful in the diagnosis of lymphoma [56] and mycobacterial infection [64]. It is associated with improved specimen acquisition, improved diagnostic yield, decreased complications or need for more invasive procedures. Diagnostic yield for lung cancer is $89 \%$ [63] and for tuberculous lymphadenopathy is $80 \%$ [61]. In children, linear probe EBUS TBNA is suitable for investigation of mediastinal or hilar lesions to diagnose leukaemia [65], lymphoma [65], sarcoidosis [66] and tuberculosis [67]. Although a 6.9-mm diameter puncturescope can be passed through a 2.5 laryngeal mask airway (LMA), ventilation is limited and a 4.0 LMA is preferable. EBUS TBNA can be performed under either general anaesthesia or sedation, and is generally well tolerated in children aged $\geqslant 9$ years [68]. Adequate sampling can be achieved in $95 \%$ of cases, although diagnostic yield may only be $47 \%$. The complication rate in children appears to be very low [65-68].

\section{Conclusions}

In children, EBUS TBNA can decrease the need for more invasive procedures, although the diameter of the puncturescope may limit its use. Practitioners performing EBUS TBNA should have specific training [69].

BOX 3

Some members of the task force perform EBUS TBNA:

at institutions with highly experienced bronchoscopy and anaesthesiology teams and in conjunction with suitably trained adult bronchoscopists

for mediastinal or hilar lesions to diagnose leukaemia, lymphoma, sarcoidosis and tuberculosis

Gaps in knowledge/recommendations for future research/training

Studies to assess whether EBUS TBNA is safe in children

Studies to assess the efficacy of EBUS TBNA in children with leukaemia/lymphoma

Studies to assess the efficacy of EBUS TBNA in children with granulomatous diseases 


\section{Foreign body extraction}

Overview of the evidence and current practice

Specific search terms were foreign body aspiration, bronchoscopy, diagnosis, removal and complication. The search yielded 154 articles, including four reviews and 18 prospective studies. Of those, 45 relevant articles were selected.

Traditionally, rigid bronchoscopy has been used for foreign body extraction with very high success rates $[3,4,70]$. It is the primary method of choice for asphyxiating foreign bodies, as it guarantees a secure airway [71-73]. In children with a history of choking, a preceding flexible bronchoscopy reduces the rate of negative rigid bronchoscopies [72, 73]. In recent years, flexible bronchoscopy has increasingly been used for foreign body extraction [74]. There is growing evidence that flexible bronchoscopes can be used as a removal tool (either alone or in combination with a rigid bronchoscope), using biopsy or grasping forceps, or wire baskets, with varying success rates [75-78]. Attempts to extract foreign bodies using a cryoprobe have been reported [79]; however, in children this technique has been associated with a high rate of complications [80]. If a flexible bronchoscope is used for foreign body extraction, immediate availability of a rigid instrument has been repeatedly recommended to guarantee safety of the procedure in case extraction attempts fail or complications occur [74, 75].

Our literature search identified no studies that systematically assessed the rate of complications with foreign body extraction. Mild-to-moderate, as well as severe complications have been reported in varying frequencies $[75,76,81,82]$. Mortality directly related to the procedure is rare [81]. Complications were found to be more frequent in children with delayed diagnosis and intervention [83].

\section{Conclusions}

There is general agreement in published guidelines that bronchoscopy should always be performed in a child with a history of choking, even in the absence of respiratory symptoms, and in a child with suggestive respiratory symptoms and/or suggestive physical and/or radiological findings, even in the absence of a history of choking [72, 84]. In this situation, rigid bronchoscopy is considered the intervention of choice (box 4). In other situations, flexible bronchoscopy is usually considered the primary tool for confirmation or exclusion of foreign body aspiration (FBA). If the foreign body type and location allows, it may be removed with the flexible bronchoscope, after securing the airway with an LMA or ETT and provided immediate availability of a rigid bronchoscope. Otherwise, the procedure is directly converted to rigid bronchoscopy.

\section{BOX 4}

All members of the task force perform bronchoscopy in children with a positive history of FBA

All members of the task force perform rigid bronchoscopy in children with a positive history of FBA and: asphyxia

a radiopaque foreign body

unilaterally diminished breath sounds

radiographic abnormalities (e.g. unilateral/focal hyperinflation)

Gaps in knowledge/recommendations for future research/training

Studies to assess the efficacy of different methods for foreign body extraction

Studies to assess the rate of complications with foreign body extraction

\section{Balloon dilation and occlusion}

\section{Overview of the evidence and current practice}

Specific search terms included balloon, ballooning, dilation, dilatation, bronchopleural fistula, haemoptysis and hemoptysis. 30 articles were selected: there were no meta-analyses or RCTs or reviews; only case series and case reports were available.

Since the first description of balloon dilation for tracheal and bronchial stenosis in 1984 [85], balloon dilation has evolved as a treatment for paediatric airway obstruction, especially laryngotracheal stenosis [86]. The procedure is usually performed under general anaesthesia alongside topical anaesthesia with lidocaine to reduce airway irritability. In general, a rigid instrument is preferred, but balloon dilation has been performed via LMA with an adult flexible bronchoscope [87] and via tracheostomy [88, 89]. Muscle relaxation is not essential, but is preferable to avoid coughing with an inflated balloon in the airway, which might cause dislodgement of the balloon, pneumothorax or 
airway rupture [89]. In children, angioplasty balloon catheters are most widely used since they impart a radially directed force against the airway lumen, which is less traumatic to the mucosa than a bougie [86, 90, 91]. Tracheobronchography with small volumes of contrast agent can be performed to assess the location, length and diameter of the stenosis [92]. The procedure begins with a balloon diameter approximating the airway diameter immediately distal to the stenosis. The balloon should be long enough to cover the stenosis and to ensure catheter stability as the balloon is inflated. The small-sized airway balloons can be visualised easily with rigid bronchoscopes during the procedure. The balloon is moved to the airway stenosis and filled with saline solution by an inflation/deflation hand pump connected to a pressure gauge that monitors pressure within the balloon. There is no clear recommendation on optimal time for balloon inflation. Some inflate for 30-60 s, or interrupt if vital signs deteriorate [93]. The procedure can be repeated with the same balloon or a larger one. In case of severe and relapsing stenosis the end-point is best determined under fluoroscopy by the disappearance of the balloon waist during inflation. Carinal stenoses are usually treated by inflating two kissing balloons side by side in both mainstem bronchi to minimise the risk of bronchial rupture $[92,94]$. Simultaneous inflation of both balloons allows adequate dilation of the trachea without overdilation of the bronchi. A technique similar to angioplasty based on the use of a standard guidewire under fluoroscopic guidance has also been described [89, 92]. Intravenous corticosteroids are useful to reduce postoperative oedema [95].

Balloon dilation has been used alone or with other techniques such as laser treatment [95-97], stent placement [98-104], mitomycin application [93], injection of intralesional corticosteroids [105] and by anaesthetists during VATS in children [106]. Serial balloon dilation has been used successfully to manage severe complications following slide tracheoplasty in children with congenital tracheal stenosis [97, 104, 105], to treat acquired tracheal [95, 107-109] or bronchial stenosis [110,111] and to treat stenosis due to granulation tissue after airway stenting [89]. In addition, bronchoplasty by balloon dilation has been used to dilate the airway segment proximal to a foreign body to facilitate extraction $[112,113]$. The use of the technique for posterior tracheal splitting [94, 96, 99, 101, 103, 114] is considered hazardous and accepted only as a lifesaving procedure or as a temporary measure until a surgical procedure can be undertaken [115].

In addition, airway ballooning can be performed to obtain endobronchial occlusion in cases of bronchopleural fistula or massive haemoptysis. The technique has been described in only a few case reports, and for bronchopleural fistula consists of placing a guidewire along the endotracheal tube and a balloon angiography catheter with a small volume of contrast agent [94, 116]. Under fluoroscopic guidance the fistula can be detected by inflating the balloon in different sites until the chest tube stops producing bubbles. The balloon should be deflated at intervals for short periods of time to reduce pressure on the bronchial walls, and care must be taken to avoid balloon overdistension. Potential adverse effects include accumulated secretions with a risk of infection, necrosis, stenosis or bronchial wall erosion with potential migration of the balloon [116]. Balloon occlusion has been detailed in only one paediatric case with life-threatening haemoptysis [94]. Due to scarce evidence, the safety and effectiveness of balloon occlusion is still unclear.

\section{Conclusions}

In specialised centres, the role of balloon dilation in the paediatric population is expanding for tracheal and bronchial stenoses. Improvement in symptoms and an increased airway diameter are expected end results after balloon dilation, but repeated procedures are usually necessary to effect a long-term improvement.

\section{BOX 5}

Some members of the task force perform balloon dilation: at institutions with highly experienced bronchoscopy and anaesthesiology teams for complications following slide tracheoplasty, and for acquired tracheal or bronchial stenosis (e.g. due to tracheal or bronchial stents)

Gaps in knowledge/recommendations for future research/training

Studies to assess the efficacy of balloon dilation in acquired tracheal stenosis compared to open surgery

Studies to assess the efficacy of balloon dilation in acquired tracheal stenosis compared to a combination of laser-assisted endoscopic surgery and balloon dilation

Studies to assess the optimal balloon diameter and inflation time in relation to the patient's age 


\section{Laser-assisted procedures}

\section{Overview of the evidence and current practice}

Specific search terms included laser, laser surgery, laser therapy and respiratory tract diseases. The search yielded 169 articles, and 40 relevant articles were selected; there were no meta-analyses or RCTs, but only (reviews of) case series and case reports available.

In the 1960s, lasers were introduced to medicine. Since then, their use has rapidly spread to diverse specialties both in adult and paediatric practice. Recent technological development, with miniaturisation of flexible and rigid bronchoscopes and their corresponding accessories, has enabled their use in the airways of small children and infants. Lasers produce a beam of monochromatic, phased and collimated light that can induce tissue vaporisation, coagulation, haemostasis and necrosis. Biological effects depend on the wavelength emitted by the laser source [117]. There are several types of lasers that are currently used in interventional bronchoscopy:

- The carbon dioxide laser is the most frequently used in the larynx, because it is air-transmitted and targeted onto a red light spot with which it is easy to aim under laryngeal suspension [94]. Conversely, when employed in the tracheobronchial tree it becomes more cumbersome because the lesions to be treated are not as easily addressed as the ones in the upper airway [118].

- The Nd:YAG laser is popular in adult practice due to its effectiveness when performing endoluminal recanalisation of the trachea or main bronchi in patients with malignant obstructive tumours. Its significant in-depth effect, with the potential risk of airway wall perforation, makes it less suitable for infants and small children [94].

- KTP (kalium-titanium-phosphate) and diode lasers are transmitted by means of a fibre and when delivered at a low power range $(<5 \mathrm{~W})$, the KTP laser can show similar tissue effects as those observed with a carbon dioxide laser. Very thin coated fibres $(200-600 \mu \mathrm{m})$ can be used with both rigid and flexible paediatric bronchoscopes through the working channel $(\geqslant 1 \mathrm{~mm}$ diameter). Alternatively, the fibre can be taped, with two or three adhesive strips, to the rod lens telescope and handled as a sole device inside the rigid bronchoscope. These types of lasers are the most frequently used when dealing with tracheobronchial lesions in the paediatric setting [117].

Bronchoscopic laser-assisted procedures are performed under general anaesthesia with muscle relaxation to avoid inaccurate targeting due to the child's movement. There is general agreement that specific safety measures must be addressed during the procedure: fractional inspired oxygen must be reduced to $<0.25$ before firing the laser beam to diminish the risk of airway ignition; smoke should be eliminated from the airway by a suction catheter connected to a side port of the rigid bronchoscope; and any flammable material in the operative field should be removed or protected against ignition [117].

Several tracheobronchial lesions can be managed effectively and safely by means of laser-assisted endoscopic surgery. Acquired web-type tracheal stenosis, without involvement of the cartilage framework, is a well-established indication and is usually treated by performing three or four radial incisions leaving intact mucosal bridges. Balloon dilation is usually performed next, to optimise the outcome. Current practice warns against circumferential resections, or in-depth procedures with cartilage exposure, because of the high risk of severe restenosis [94]. Granulomas, or obstructive granulation tissue, can be photoresected in a safe and haemostatic way by placing the tip of the laser fibre on the protruding surface and vaporising or carbonising the lesion. Excision of suprastomal granulomas prior to tracheostomy tube removal appears to be the most frequent indication in children $[119,120]$. In addition, endoscopic laser therapy has been reported in the management of symptomatic tracheal pouches, sealing of recurrent tracheoesophageal fistulas, repair of laryngo-tracheal clefts and splitting complete tracheal rings in congenital tracheal stenosis [96, 121-123].

In contrast to adult practice, laser photoresection of endoluminal airway tumours in children has been reported infrequently and for some entities is not the recommended treatment option. Some authors have reported bronchoscopic resection of inflammatory pseudotumors, endobronchial carcinoids and haemangiomas [124-127]. Respiratory papillomas affecting the tracheobronchial tree can be removed endoscopically with a laser or microdebrider [128].

In primary tuberculosis, endoscopic laser-assisted debulking of enlarged lymph nodes with endobronchial involvement has been reported [117].

\section{Conclusions}

Despite the limited information available, indications for laser-assisted endoscopic procedures in the paediatric airway appear to be increasing. There are no well-established criteria for laser intervention in children, and each procedure should be considered on an individual basis. 


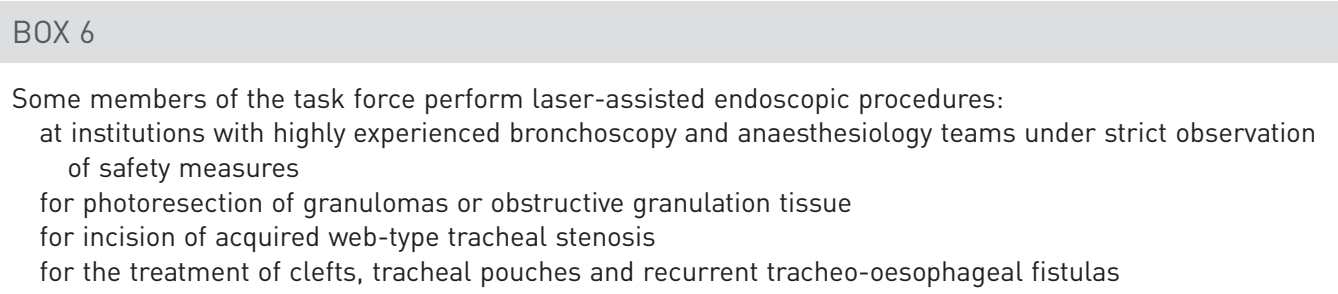

\section{Gaps in knowledge/recommendations for future research/training}

Studies to assess the most adequate type of laser to be used in the paediatric airway

Studies to assess the optimal laser beam power and way of delivery (continuous, pulsed or ultrapulsed) in relation to specific lesions

Studies to assess the efficacy of laser-assisted endoscopic procedures alone compared to a combination of laser-assisted procedures and balloon dilation

\section{Airway stents}

\section{Overview of the evidence and current practice}

Specific search terms included airway, bronchus, trachea and stent. 31 relevant articles were selected; there were no meta-analyses or RCTs, but only reviews, case series and case reports available.

Airway stents are routinely placed in adults, mostly for malignant diseases as palliative measures. Stent placement in children must take account for the soft airway structures, the considerable luminal growth that needs to be accommodated by the implants and the usually histologically benign nature of the airway obstruction, in contrast to adults. There are several types of stents currently used in interventional bronchoscopy:

- Silicone stents tend to dislocate [129], and deaths due to airway obstruction caused by dislocated stents have been reported [130]. It has been recommended that these stents should not be used in central airways other than after surgery [131].

- Metal mesh stents (bare or partially covered) tend to cause granulation or wall damage and need to be considered permanent (ingrowth). Thus, they may cause secondary stenosis with airway growth [131].

- Biodegradable stents have theoretical advantages in some circumstances, but they have a tendency to dissolve too early and severe complications (death due to stent fragmentation and aspiration) have been reported [132, 133]. Clearly, biodegradable material would be preferable, as it could avoid the long-term consequences of ingrown metal mesh stents as well as the secretion retention, granulation and displacement issues of removable covered or silicone stents. Currently, there is insufficient experience to draw conclusions regarding the utility of biodegradable stents, and their use is restricted to research protocols. Material improvements and more experience may change this in the future.

A systematic review of earlier case series with mostly metal and some silicone stents, including 121 cases, documented an initial success rate of $92.6 \%$ with a mortality of $11.6 \%$ [131]. In the same review, a second group of publications focusing on stent-related complications (49 cases) was analysed and showed a $16.3 \%$ stent-related mortality; both series taken together amounted to a $12.9 \%$ mortality. Subsequently, a number of retrospective case series have been published. Two series with five patients each reported the long-term outcome of stents used in tracheal stenosis after endoscopic dilation, with good functional outcomes, but a high complication rate $[103,134]$. Another case series reported on rapamycin-eluting stents after balloon dilation of congenital tracheal stenosis in eight infants, but with only a short follow-up [135]. A retrospective study of 21 severely sick patients in whom stenting was used as the last resort reported clinical improvement in 18 (85\%) patients with complications requiring endoscopic treatment or removal of the stent in five (27\%) of them; stent related mortality was $4 \%$ [136]. Similarly, a recent study on the use of stents in children with severe airway problems due to mucopolysaccharidosis reported considerable and partly severe complications [137]. Another article reported on the use of endotracheal nitinol stents in seven children, again describing a high frequency of complications [138]. A large retrospective case series of 100 patients, in whom 120 metal, 112 silicone and three biodegradable stents were placed, included children with less severe disease than previous series [129]. Although patient selection in this study was different to most other published series, complications were seen in $71-87 \%$, according to stent type. Typical complications include the formation of major granulation tissue requiring laser treatment and/or stent replacement, stent dislocation, ovalisation requiring dilation, airway perforation and infection $[129,131]$. 
Conclusions

In experienced hands, the placement of airway stents is technically feasible, with little directly procedure-related morbidity or mortality. Stent implantation for benign paediatric airway disease can be useful either for temporary luminal stabilisation after airway surgery or for relief of severe airway malacia or stenosis when all other medical and surgical options have failed or are contraindicated. Complications are encountered frequently and their treatment requires considerable expertise, which must be available at centres offering this treatment. Although the usefulness of stents as temporary scaffolding appears to be well established in children post airway surgery [97, 104], available data do not allow a firm conclusion for stent placement in defined clinical circumstances. Metal stents should be avoided in children with benign disease due to the difficulty of removal and complications [139]. If stents are used, comprehensive information must be given to parents/patients about their possible benefits and risks to allow informed consent.

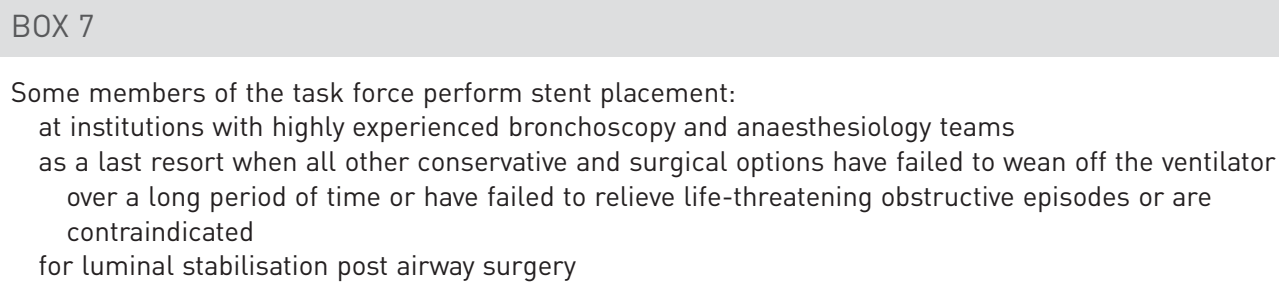

\section{Microdebriders}

Overview of the evidence and current practice

Specific search terms included microdebrider and endoscopy. The search yielded five articles; there were no meta-analyses or RCTs, but only reviews and case reports available.

The use of microdebriders has increased in the past decade in adults and children, in a wide spectrum of diseases, from the nasal cavity to the bronchi, but especially recurrent respiratory papillomatosis [140]. There are many microdebriders available with varying diameters, lengths, angles, rotational properties and tip configurations (aggressive cutting or delicate tips). In the distal tip, a vacuum pulls the tissue and the rotating blade amputates it. Due to the lack of haemostatic capability, topical epinephrine or oxymetazoline or, rarely, endoscopic cautery devices are used to control bleeding. Microdebriders have been used for the removal of granulations and thin scar bands in the trachea [141] and in the management of excess suprastromal granulation tissue following tracheostomy [142].

\section{Conclusions}

Due to the scarce experience reported, there are no well-established indications for the use of microdebriders in children. This technique should only be performed at institutions with highly experienced bronchoscopy and anaesthesiology teams. None of the task force members uses microdebriders.

\section{Gaps in knowledge/recommendations for future research/training}

Studies to assess the utility of microdebriders in children

\section{Cryotherapy \\ Overview of the evidence and current practice}

Specific search terms included cryotherapy and endoscopy. The search yielded 17 articles, of which two were selected; there were no meta-analyses or RCTs or reviews, but only case reports available.

Cryotherapy is performed by using a freezing instrument during bronchoscopy. The cryogen is liquid carbon dioxide. An ice ball is generated by inserting the freezing probe into the lesion, then the crystallised lesion is removed from the airway. This procedure is repeated several times to remove the lesion. To stop bleeding, argon plasma coagulation is used. In children, cryotherapy has been used in 
association with argon plasma coagulation for removing a low-grade bronchial mucoepidermoid carcinoma [143] and an inflammatory myofibroblastic tumour [144].

\section{Conclusions}

Due to the scarce experience reported, there are no established indications for cryotherapy in children. None of the task force members uses cryotherapy.

\section{Gaps in knowledge/recommendations for future research/training}

Studies to assess the utility of cryotherapy in children

\section{Endoscopic intubation}

Overview of the evidence and current practice

Specific search terms included endoscopic intubation. The search yielded 11 articles of different types; there was no meta-analysis available.

Flexible bronchoscopic intubation represents the most frequent primary indication for interventional bronchoscopy in paediatric intensive care patients [145, 146], particularly for critically ill [147] and syndromic [148] patients. In children nasal intubation tends to be easier than oral intubation, because the angle around the base of the tongue is less sharp than in adults. Moreover, it is preferred to oral intubation when full access to the oral cavity is required for surgery or when the mouth opening is limited. Oral flexible intubation can be performed via a modified oropharyngeal Guedel airway (cut through its entire dorsal length to facilitate the removal of the flexible bronchoscope) or via LMA [149]. Nasal intubation can be achieved either through an appropriately modified ventilation mask (Frey type) or mask adapter with port opening, or without an aiding device. The ETT is mounted on a flexible bronchoscope (with an external diameter $\geqslant 1 \mathrm{~mm}$ smaller than the ETT diameter) and secured near the proximal end. The patient's head is maintained in neutral position. The lubricated bronchoscope is introduced via a nostril or the mouth and advanced into the larynx after topical lidocaine administration. Once in the trachea the ETT is advanced over the bronchoscope [4]. To avoid getting hung up at the arytenoids, a $90^{\circ}$ counterclockwise rotation of the ETT has been recommended [150].

\section{Conclusions}

The role of flexible bronchoscopy in the intubation of children with difficult airways is well established. This technique is usually available in every paediatric intensive care unit and operating room and it is usually a skill of every paediatric anaesthesiologist. All members of the task force perform flexible bronchoscopic intubation in children with difficult airways.

Gaps in knowledge/recommendations for future research/training

Every paediatric bronchoscopist should be trained in endoscopic intubation of children of all ages

\section{Application of drugs and other liquids}

Several bronchoscopic techniques for local drug application have been developed. They are mostly applied in adults; for children, there are only occasional reports or small case series available.

\section{Tracheo-oesophageal fistula repair}

Overview of the evidence and current practice

Specific search terms included tracheoesophageal fistula. The search yielded 26 articles of different types; there was no meta-analysis available.

Tracheo-oesophageal fistula (TOF) repair has been performed via bronchoscopy as an alternative to open surgery. Different techniques have been described to achieve endoscopic TOF closure, such as injection of a sealant, de-epithelialisation of the fistula, or a combination of both [151-154]. These techniques have a low risk and are associated with less morbidity, but a lower success rate, with very high refistulation rates [153]. Endoscopic closure is preferred in recurrent TOF after unsuccessful attempts with open surgery and isolated TOF without oesophageal atresia $[155,156]$. 
Conclusions

Due to the scarce experience reported, the most appropriate technique for endoscopic closure of a TOF is unclear. With relatively low success rates, only recurrent TOF or a second, so far unnoticed, fistula (i.e. in the already operated child) appears to be an indication for endoscopic closure. Some members of the task force perform endoscopic TOF repair.

Gaps in knowledge/recommendations for future research/training

Studies to assess the efficacy of endoscopic TOF repair

\section{Bronchopleural fistula treatment}

\section{Overview of the evidence and current practice}

Specific search terms included bronchopleural fistula. The search yielded six articles; there was no meta-analysis available.

In the paediatric literature, aetiologies for bronchopleural fistula (BPF) have included mainly empyema/ necrotising pneumonia, but also FBA and iatrogenic causes. Flexible bronchoscopy has been used to confirm and/or treat persistent BPF [157, 158]. When a BPF is not clearly visible on bronchoscopy, selective bronchography at the suspected site may be utilised [159]. Alternatively, selective instillation of methylene blue into segmental bronchi with its subsequent appearance in the chest drainage may help confirm and localise BPF [160]. The technique of endobronchial occlusion using a balloon is described earlier.

\section{Conclusions}

In clinical practice, depending on the individual situation and given the difficulty and the limited experience with the procedure, other options (e.g. wait and see, surgery, application of a sealant via the drain or intrabronchial valves) are usually preferred over interventional bronchoscopy. None of the task force members performs endoscopic bronchopleural fistula treatment.

Gaps in knowledge/recommendations for future research/training

Studies to assess the utility of endoscopic bronchopleural fistula treatment

\section{Atelectasis treatment}

Overview of the evidence and current practice

Specific search terms included atelectasis. The search yielded 33 articles; there was no meta-analysis available.

Atelectasis usually resolves spontaneously. Persistent and recurrent atelectasis are important indications for diagnostic flexible bronchoscopy [3,4]. Depending on the endoscopic findings, further targeted actions may be undertaken, such as suctioning, foreign body extraction, sampling of various materials and other more specific procedures. An attempt to re-inflate the atelectatic lung parenchyma with repeated saline lavages is considered standard practice [4]. In refractory atelectasis, bronchoscopic applications of various drugs have been tried. Surfactant administration was reported to improve ventilation by re-aeration of atelectatic regions and help wean children from mechanical ventilation [161]. Similarly, bronchoscopically administered recombinant human DNase has been used in cystic fibrosis patients [162], non-cystic fibrosis patients [163], and premature neonates [164], with variable success.

\section{Conclusions}

Due to the scarce experience reported, and with the vast majority of atelectases resolving spontaneously, the most appropriate endoscopic treatment of persistent atelectasis is unknown. All members of the task force perform endoscopic treatment of atelectasis, with various agents such as acetylcysteine, saline, sodium bicarbonate and recombinant human DNase.

\section{Gaps in knowledge/recommendations for future research/training}

Studies to assess the efficacy of endoscopic treatment of persistent atelectasis with various agents 


\section{Plastic bronchitis treatment}

Overview of the evidence and current practice

Specific search terms included plastic bronchitis. The search yielded 14 articles; there was no meta-analysis available.

Management of plastic bronchitis is difficult, and aggressive measures to remove casts combined with intensive medical care are often necessary. In refractory cases bronchoscopic drug application has been tried. It appears that endoscopic administration of tissue plasminogen activator (tPA) is a safe and effective option [165]. Airway clearance with inhaled tPA may be effective in both patients with inflammatory disease and patients undergoing surgery for congenital heart disease $[165,166]$. In addition, intrabronchial DNase [167] and nebulised hypertonic saline have been reported to be beneficial [168].

\section{Conclusions}

Due to the scarce experience reported, the most appropriate (endoscopic) treatment of plastic bronchitis is not known. All members of the task force perform endoscopic treatment of plastic bronchitis with various agents, including tPA.

\section{Gaps in knowledge/recommendations for future research/training}

Studies to assess the efficacy of endoscopic treatment of plastic bronchitis with various agents

\section{Haemoptysis control \\ Overview of the evidence and current practice}

Specific search terms included haemoptysis and hemoptysis. The search yielded 13 articles; there was no meta-analysis available.

Haemoptysis is a relatively uncommon indication for diagnostic bronchoscopy in children. Flexible bronchoscopy is generally contraindicated for investigation or treatment of massive haemoptysis [3]. Effective intervention in patients with excessive bleeding into the airways may include endoscopic evaluation with the rigid bronchoscope and possibly local application of vasoconstrictors. Therapeutic lavages with epinephrine (1:10000 or 1:20000 solution) or cold saline at $4^{\circ} \mathrm{C}$ have been suggested [169].

\section{Conclusions}

In clinical practice, flexible or rigid bronchoscopy with or without application of cold saline or adrenaline are used to control haemoptysis depending on the individual situation. Some members of the task force perform therapeutic lavages with epinephrine or cold saline.

\section{Gaps in knowledge/recommendations for future research/training}

Studies to assess the role of endoscopic evaluation and therapeutic lavages in the multidisciplinary management of patients with massive haemoptysis

\section{Caregiver perspectives}

Specific search terms included bronchoscope, bronchoscopy, communication, concerns, experience, foreign body aspiration, foreign object removal, interventional bronchoscopy, parent, patient and perspective.

Caregiver experiences relate to two uses of bronchoscopy: exploratory use and foreign body removal. Key themes are understanding, reassurance, discomfort and sedation. Postbronchoscopy caregiver reflections are generally positive, due to infrequent adverse side-effects and the outcome of knowing more about their child's condition or successful treatment.

\section{Exploratory bronchoscopy}

Caregivers are often anxious about the procedure, which increases with lack of information and reassurance from healthcare professionals before and after the procedure. Information about noninvasive alternatives is desirable, with interventional bronchoscopy prescribed only when there are no noninvasive alternatives [115]. Caregivers recognise the value of bronchoscopy to gain information about a respiratory condition, but have concerns about the sedation of young children [170]. Anxiety could be relieved to a large extent with information and reassurance on the purpose of the procedure; sedation/anaesthesia and 
side-effects, e.g. disorientation; discomfort, e.g. sore throat, coughing; duration of the procedure and side-effects; and caregiver accompaniment, e.g. staying with the child until sedated $[115,170]$.

\section{Foreign body removal}

Caregivers and primary care professionals should be able to recognise the potential signs of FBA, especially in nonemergency situations, e.g. when a caregiver visits the local doctor with a child with acute-onset breathing difficulties [171-173]. Recognising FBA as a potential cause of breathing difficulties and performing a bronchoscopy within $24 \mathrm{~h}$ of symptom onset reduces the risk of complications [83, 174]. As a preventative strategy, primary care professionals are ideally placed to educate parents about FBA from birth and during early childhood [173].

Caregiver education and awareness is essential in reducing the incidence of FBA in preschool children $[171,172,174]$. Caregivers and healthcare professionals have called for the general public, and especially parents of young children, to be made aware of the risks of giving children foods that are too small for them to chew and swallow safely, or toys with small detachable parts, and how to identify the signs of FBA [171, 174-176]. If caregivers are aware of the risks, and supervise the handling of foreign objects by children, any ingestion, insertion or inhalation can be reported and responded to promptly, thus reducing the risk of damage or even death [175]. Caregiver information is essential from the age at which children start eating solid foods, with nuts and crunchy foods such as carrots of particular concern [174, 177]. Information is also vital at the point of discharge following a FBA incident to prevent reoccurrence [176, 177].

\section{Conclusion}

The advent of suitably sized paediatric bronchoscopes with a working channel provides the well-trained bronchoscopist the ability to offer appropriately selected children interventional bronchoscopic procedures. However, the number of children requiring interventional bronchoscopic procedures is small constraining the training experience for paediatric bronchoscopists. Yet, for an individual child an interventional bronchoscopic procedure may significantly limit morbidity from either the underlying disease process or from a more invasive procedure.

Adult bronchoscopists possess greater experience and training in the field, but are not familiar with the unpredictable nature of the paediatric airway. Novel approaches in the training of paediatric bronchoscopists in collaboration with adult bronchoscopists needs to be considered, as does the establishment of paediatric centres of excellence in interventional bronchoscopy to assure that individual practitioners maintain their skills.

The scarcity of published studies in this field in general underlines the need for further research, but meaningful advancement in the field will require multicentre collaboration. The highlighted gaps in knowledge throughout the manuscript serve as a call to paediatric bronchoscopists to work and learn together for the benefit of children with airway disorders.

\section{References}

1 Jackson C, Jackson CL. Diseases of the air and food passages of foreign body origin. Laryngoscope 1936 ; $46: 814$.

2 Wood RE, Fink RJ. Applications of flexible fiberoptic bronchoscopes in infants and children. Chest 1978; 73: 737-740.

3 Midulla F, de Blic J, Barbato A, et al. Flexible endoscopy of paediatric airways. Eur Respir J 2003; 22: 698-708.

4 Faro A, Wood RE, Schechter MS, et al. Official American Thoracic Society technical standards: flexible airway endoscopy in children. Am J Respir Crit Care Med 2015; 191: 1066-1080.

5 Bush A, Cunningham S, de Blic J, et al. European protocols for the diagnosis and initial treatment of interstitial lung disease in children. Thorax 2015; 70: 1078-1084.

6 Kurland G, Deterding RR, Hagood JS, et al. An official American Thoracic Society clinical practice guideline: classification, evaluation, and management of childhood interstitial lung disease in infancy. Am J Respir Crit Care Med 2013; 188: 376-394.

7 Wood RE. Whole lung lavage. In: Priftis KN, Anthracopoulos MB, Eber E, et al., eds. Paediatric Bronchoscopy. Progress in Respiratory Research. Basel, Karger, 2010; pp. 75-82.

8 Wilson CA, Wilmshurst SL, Black AE. Anesthetic techniques to facilitate lung lavage for pulmonary alveolar proteinosis in children - new airway techniques and a review of the literature. Paediatr Anaesth 2015; 25: 546-553.

9 Reiter K, Schoen C, Griese M, et al. Whole-lung lavage in infants and children with pulmonary alveolar proteinosis. Paediatr Anaesth 2010; 20: 1118-1123.

10 Paquet C, Karsli C. Technique of lung isolation for whole lung lavage in a child with pulmonary alveolar proteinosis. Anesthesiology 2009; 110: 190-192.

11 DiFusco LA, Verma RK. Whole-lung lavage for pediatric patients with pulmonary alveolar proteinosis. AORN $J$ 2013; 98: 50-67.

12 de Blic J. Pulmonary alveolar proteinosis in children. Paediatr Respir Rev 2004; 5: 316-322.

13 Gonçalves BM, Teixeira VC, Bittencourt PF. Anesthesia for lung lavage in pediatric patient with pulmonary alveolar proteinosis. Rev Bras Anestesiol 2012; 62: 269-273. 
Hodges O, Zar HJ, Mamathuba R, et al. Bilateral partial lung lavage in an infant with pulmonary alveolar proteinosis. Br J Anaesth 2010; 104: 228-230.

Mahut B, de Blic J, Le Bourgeois M, et al. Partial and massive lung lavages in an infant with severe pulmonary alveolar proteinosis. Pediatr Pulmonol 1992; 13: 50-53.

Tsai WC, Lewis D, Nasr SZ, et al. Liquid ventilation in an infant with pulmonary alveolar proteinosis. Pediatr Pulmonol 1998; 26: 283-286.

Froudarakis ME, Koutsopoulos A, Mihailidou HP. Total lung lavage by awake flexible fiberoptic bronchoscope in a 13-year-old girl with pulmonary alveolar proteinosis. Respir Med 2007; 101: 366-369.

Yamamoto $\mathrm{H}$, Yamaguchi E, Agata $\mathrm{H}$, et al. A combination therapy of whole lung lavage and GM-CSF inhalation in pulmonary alveolar proteinosis. Pediatr Pulmonol 2008; 43: 828-830.

Doğru D, Yalçin E, Aslan AT, et al. Successful unilateral partial lung lavage in a child with pulmonary alveolar proteinosis. J Clin Anesth 2009; 21: 127-130.

Garg G, Sachdev A, Gupta D. Pulmonary alveolar proteinosis. Indian Pediatr 2009; 46: 521-523.

DiBlasi RM, Crotwell D, Geiduscheck JM, et al. Therapeutic bilateral lung lavage in a child with pulmonary alveolar proteinosis. Pediatr Crit Care Med 2010; 11: e28-e31.

Suzuki T, Sakagami T, Young LR, et al. Hereditary pulmonary alveolar proteinosis: pathogenesis, presentation, diagnosis, and therapy. Am J Respir Crit Care Med 2010; 182: 1292-1304.

Griese M, Ripper J, Sibbersen A, et al. Long-term follow-up and treatment of congenital alveolar proteinosis. BMC Pediatr 2011; 11: 72.

Hildebrandt J, Yalçin E, Bresser HG, et al. Characterization of CSF2RA mutation related juvenile pulmonary alveolar proteinosis. Orphanet J Rare Dis 2014; 9: 171.

Enaud L, Hadchouel A, Coulomb A, et al. Pulmonary alveolar proteinosis in children on La Réunion Island: a new inherited disorder? Orphanet J Rare Dis 2014; 9: 85.

Ceruti M, Rodi G, Stella GM, et al. Successful whole lung lavage in pulmonary alveolar proteinosis secondary to lysinuric protein intolerance: a case report. Orphanet J Rare Dis 2007; 2: 14 intolerance. J Inherit Metab Dis 2015; 38: 257-263.

Palmeri S, Tarugi P, Sicurelli F, et al. Lung involvement in Niemann-Pick disease type C1: improvement with bronchoalveolar lavage. Neurol Sci 2005; 26: 171-173.

Uyan ZS, Karadağ B, Ersu R, et al. Early pulmonary involvement in Niemann-Pick type B disease: lung lavage is not useful. Pediatr Pulmonol 2005; 40: 169-172.

Gülhan B, Ozçelik U, Gürakan F, et al. Different features of lung involvement in Niemann-Pick disease and Gaucher disease. Respir Med 2012; 106: 1278-1285.

Ciravegna B, Sacco O, Moroni C, et al. Mineral oil lipoid pneumonia in a child with anoxic encephalopathy: treatment by whole lung lavage. Pediatr Pulmonol 1997; 23: 233-237.

Midulla F, Strappini PM, Ascoli V, et al. Bronchoalveolar lavage cell analysis in a child with chronic lipid pneumonia. Eur Respir J 1998; 11: 239-242.

Zanetti G, Marchiori E, Gasparetto TD, et al. Lipoid pneumonia in children following aspiration of mineral oil used in the treatment of constipation: high-resolution CT findings in 17 patients. Pediatr Radiol 2007; 37: $1135-1139$.

Sias SM, Daltro PA, Marchiori E, et al. Clinic and radiological improvement of lipoid pneumonia with multiple bronchoalveolar lavages. Pediatr Pulmonol 2009; 44: 309-315.

Sias SM, Ferreira AS, Daltro PA, et al. Evolution of exogenous lipoid pneumonia in children: clinical aspects, radiological aspects and the role of bronchoalveolar lavage. J Bras Pneumol 2009; 35: 839-845.

Azevedo Sias S, Oliveira Caetano R, Dutra Comarella J, et al. Successful treatment of lipoid pneumonia associated with bowel obstruction by Ascaris lumbricoides. J Trop Pediatr 2011; 57: 269-273.

Buda P, Wieteska-Klimczak A, Własienko A, et al. Lipoid pneumonia - a case of refractory pneumonia in a child treated with ketogenic diet. Pneumonol Alergol Pol 2013; 81: 448-452.

Faro A, Visner G. The use of multiple transbronchial biopsies as the standard approach to evaluate lung allograft rejection. Pediatr Transplant 2004; 8: 322-328.

Wong JY, Westall GP, Snell GI. Bronchoscopic procedures and lung biopsies in pediatric lung transplant recipients. Pediatr Pulmonol 2015; 50: 1406-1419.

273-280.

Elizur A, Faro A, Huddleston CB, et al. Lung transplantation in infants and toddlers from 1990 to 2004 at St. Louis Children's Hospital. Am J Transplant 2009; 9: 719-726.

Benden C, Harpur-Sinclair O, Ranasinghe AS, et al. Surveillance bronchoscopy in children during the first year after lung transplantation: is it worth it? Thorax 2007; 62: 57-61. biopsy in immunocompetent children with chronic interstitial lung disease. J Pediatr 1997; 131: 565-569.

Phadke SM, Chini BA, Patton D, et al. Relapsed non-Hodgkin's lymphoma diagnosed by flexible bronchoscopy. Pediatr Pulmonol 2002; 34: 488-490.

Djordjević M, Minić P, Sarajlija A, et al. Pulmonary involvement in siblings with Gaucher disease type III. Vojnosanit Pregl 2011; 68: 1071-1074.

Inoue T, Toyoshima K, Kikui M. Idiopathic bronchiolitis obliterans organizing pneumonia (idiopathic BOOP) in childhood. Pediatr Pulmonol 1996; 22: 67-72.

McClellan JS, Albers GM, Noyes BE, et al. B-lymphocyte aggregates in alveoli from a child with hypersensitivity pneumonitis (bird breeders lung). Ann Allergy Asthma Immunol 1999; 83: 357-360.

Najada AS, Dahabreh MM. Pulmonary haemosiderosis in a 13-year-old girl with coeliac disease after 3 months on a gluten-free diet: case report and review of the literature. Ann Trop Paediatr 2010; 30: 249-253.

Schmidt H, Lörcher U, Kitz R, et al. Pulmonary alveolar microlithiasis in children. Pediatr Radiol 1996; 26 : 33-36.

Wallis C, Whitehead B, Malone $\mathrm{M}$, et al. Pulmonary alveolar microlithiasis in childhood: diagnosis by transbronchial biopsy. Pediatr Pulmonol 1996; 21: 62-64. 
Marques VL, Gomes RC, Viola GR, et al. Pulmonary cryptococcosis in childhood systemic lupus erythematosus and Sjögren syndrome overlap: a rare opportunistic infection. Lupus 2013; 22: 1409-1412.

Bush A, Cunningham S, de Blic J, et al. European protocols for the diagnosis and initial treatment of interstitial lung disease in children. Thorax 2015; 70: 1078-1084.

Regamey N, Hilliard TN, Saglani S, et al. Quality, size, and composition of pediatric endobronchial biopsies in cystic fibrosis. Chest 2007; 131: 1710-1717.

Salva PS, Theroux C, Schwartz D. Safety of endobronchial biopsy in 170 children with chronic respiratory symptoms. Thorax 2003; 58: 1058-1060.

Molina-Teran A, Hilliard TN, Saglani S, et al. Safety of endobronchial biopsy in children with cystic fibrosis Pediatr Pulmonol 2006; 41: 1021-1024.

Wahidi MM, Herth F, Yasufuku K, et al. Technical aspects of endobronchial ultrasound-guided transbronchial needle aspiration: CHEST guideline and expert panel report. Chest 2016; 149: 816-835.

Huang JA, Browning R, Wang KP. Counterpoint: Should endobronchial ultrasound guide every transbronchial needle aspiration of lymph nodes? No. Chest 2013; 144: 734-737.

Bilaçeroğlu S, Günel $\mathrm{O}$, Eris N, et al. Transbronchial needle aspiration in diagnosing intrathoracic tuberculous lymphadenitis. Chest 2004; 126: 259-267.

Goussard P, Gie RP, Kling S, et al. The diagnostic value and safety of transbronchial needle aspiration biopsy in children with mediastinal lymphadenopathy. Pediatr Pulmonol 2010; 45: 1173-1179.

Wang Memoli JS, Nietert PJ, Silvestri GA. Meta-analysis of guided bronchoscopy for the evaluation of the pulmonary nodule. Chest 2012; 142: 385-393.

Herth F, Becker HD, Manegold C, et al. Endobronchial ultrasound (EBUS) - assessment of a new diagnostic tool in bronchoscopy for staging of lung cancer. Onkologie 2001; 24: 151-154.

Casal RF, Staerkel GA, Ost D, et al. Randomized clinical trial of endobronchial ultrasound needle biopsy with and without aspiration. Chest 2012; 142: 568-573.

Silvestri GA, Gonzalez AV, Jantz MA, et al. Methods for staging non-small cell lung cancer: diagnosis and management of lung cancer, 3rd ed: American College of Chest Physicians evidence-based clinical practice guidelines. Chest 2013; 143: Suppl. 5, e211S-e250S.

$\mathrm{Li}$ W, Zhang T, Chen Y, et al. Diagnostic value of convex probe endobronchial ultrasound-guided transbronchial needle aspiration in mediastinal tuberculous lymphadenitis: a systematic review and meta-analysis. Med Sci Monit 2015; 21: 2064-2072.

Gilbert CR, Feller-Kopman D, Akulian J, et al. Interventional pulmonology procedures in the pediatric population. Pediatr Pulmonol 2014; 49: 597-604.

Wurzel DF, Steinfort DP, Massie J, et al. Paralysis and a perihilar protuberance: an unusual presentation of sarcoidosis in a child. Pediatr Pulmonol 2009; 44: 410-414.

Madan K, Ayub II, Mohan A, et al. Endobronchial ultrasound-guided transbronchial needle aspiration (EBUS-TBNA) in mediastinal lymphadenopathy. Indian J Pediatr 2015; 82: 378-380.

Gilbert CR, Chen A, Akulian JA, et al. The use of convex probe endobronchial ultrasound-guided transbronchial needle aspiration in a pediatric population: a multicenter study. Pediatr Pulmonol 2014; 49: 807-815.

Ernst A, Silvestri GA, Johnstone D. Interventional pulmonary procedures: guidelines from the American College of Chest Physicians. Chest 2003; 123: 1693-1717.

Divisi D, Di Tommaso S, Garramone M, et al. Foreign bodies aspirated in children: role of bronchoscopy. Thorac Cardiovasc Surg 2007; 55: 249-252.

Lima JAB, Fischer GB. Foreign body aspiration in children. Paediatr Respir Rev 2002; 3: 303-307.

Martinot A, Closset M, Marquette $\mathrm{CH}$, et al. Indications for flexible versus rigid bronchoscopy in children with suspected foreign-body aspiration. Am J Respir Crit Care Med 1997; 155: 1676-1679.

Righini CA, Morel N, Karkas A, et al. What is the diagnostic value of flexible bronchoscopy in the initia investigation of children with suspected foreign body aspiration? Int J Pediatr Otorhinolaryngol 2007; 71: $1383-1390$.

4 Schramm D, Ling K, Schuster A, et al. Foreign body removal in children: recommendations versus real life - a survey of current clinical management in Germany. Pediatr Pulmonol 2017; 52: 656-661.

Swanson KL, Prakash UBS, Midthun DE, et al. Flexible bronchoscopic management of airway foreign bodies in children. Chest 2002; 121: 1695-1700.

Tang LF, Xu YC, Wang YS, et al. Airway foreign body removal by flexible bronchoscopy: experience with 1027 children during 2000-2008. World J Pediatr 2009; 5: 191-195.

Rodrigues AJ, Scussiatto EA, Jacomelli M, et al. Bronchoscopic techniques for removal of foreign bodies in children's airways. Pediatr Pulmonol 2012; 47: 59-62.

Tenenbaum T, Kähler G, Janke C, et al. Management of foreign body removal in children by flexible bronchoscopy. J Bronchology Interv Pulmonol 2017; 24: 21-28.

Zhang L, Yin Y, Zhang J, et al. Removal of foreign bodies in children's airways using flexible bronchoscopic $\mathrm{CO}_{2}$ cryotherapy. Pediatr Pulmonol 2016; 51: 943-949. in children. Pediatr Pulmonol 2016; 51: 889-891.

Boufersaoui A, Smati L, Benhalla KN, et al. Foreign body aspiration in children: experience from 2624 patients. Int J Pediatr Otorhinolaryngol 2013; 77: 1683-1688.

Fidkowski CW, Zheng H, Firth PG. The anesthetic considerations of tracheobronchial foreign bodies in children: a literature review of 12,979 cases. Anesth Analg 2010; 111: 1016-1025.

Shlizerman L, Mazzawi S, Rakover Y, et al. Foreign body aspiration in children: the effects of delayed diagnosis. Am J Otolaryngol 2010; 31: 320-324.

Barrios Fontoba JE, Gutierrez C, Lluna J, et al. Bronchial foreign body: should bronchoscopy be performed in all patients with a choking crisis? Pediatr Surg Int 1997; 12: 118-120.

Cohen MD, Weber TR, Rao CC. Balloon dilatation of tracheal and bronchial stenosis. AJR Am J Roentgenol 1984; 142: 477-478.

Chueng K, Chadha NK. Primary dilatation as a treatment for pediatric laryngotracheal stenosis: a systematic review. Int J Pediatr Otorhinolaryngol 2013; 77: 623-628. 
Xin Y, Wang G, Gao X, et al. Interventional bronchoscopy via laryngeal mask airway (LMA) under general anesthesia in children using adult flexible bronchoscope. Kuwait Med J 2016; 48: 317-322.

Jaffe RB. Balloon dilation of congenital and acquired stenosis of the trachea and bronchi. Radiology 1997; 203: 405-409.

McLaren CA, Elliott MJ, Roebuck DJ. Tracheobronchial intervention in children. Eur J Radiol 2005; 53: 22-34.

Messineo A, Narne S, Mognato G, et al. Endoscopic dilation of acquired tracheobronchial stenosis in infants. Pediatr Pulmonol 1997; 23: 101-104.

Hebra DD, Powell CD, Smith HB, et al. Balloon tracheoplasty in children: results of a 15-year experience. J Pediatr Surg 1991; 26: 957-961.

Roebuck DJ, Hogan MJ, Connolly B, et al. Interventions in the chest in children. Tech Vasc Interv Radiol 2011; 14: 8-15.

Ortiz R, Dominguez E, De La Torre C, et al. Early endoscopic dilation and mitomycin application in the treatment of acquired tracheal stenosis. Eur J Pediatr Surg 2014; 24: 39-45.

Donato LL, Mai Hong Tran T, Ammouche C, et al. Pediatric interventional bronchoscopy. Clin Chest Med 2013; 34: 569-582.

Guarisco JL, Yang CJ. Balloon dilation in the management of severe airway stenosis in children and adolescents. J Pediatr Surg 2013; 48: 1676-1681.

Othersen HB Jr, Hebra A, Tagge EP. A new method of treatment for complete tracheal rings in an infant: endoscopic laser division and balloon dilation. J Pediatr Surg 2000; 35: 262-264.

Antón-Pacheco JL, Comas JV, Luna C, et al. Treatment strategies in the management of severe complications following slide tracheoplasty in children. Eur J Cardiothorac Surg 2014; 46: 280-285.

Nicolai T, Huber RM, Pfeifer KJ, et al. Bilateral bronchial balloon dilatation and Strecker stent implantation in a ventilated child with malignant carinal stenosis. Intensive Care Med 1996; 22: 482-485.

Maeda K, Yasufuku M, Yamamoto T. A new approach to the treatment of congenital tracheal stenosis: balloon tracheoplasty and expandable metallic stenting. J Pediatr Surg 2001; 36: 1646-1649.

Aguilera IM, Walker RW, Dearlove OR. Postintubation tracheal stenosis in an 11-year-old boy: a surgical and anaesthetic challenge. Paediatr Anaesth 2002; 12: 733-737.

Hyun JK, Shin JH, Hong SJ, et al. Treatment of congenital tracheal stenosis with balloon-assisted posterior tracheal splitting and temporary placement of a covered retrievable metallic stent. J Vasc Interv Radiol 2005; 16: 287-291.

2 Törer B, Gülcan H, Oğuzkurt L, et al. Use of balloon-expandable metallic stent in a premature infant with congenital tracheobronchial stenosis. Pediatr Pulmonol 2008; 43: 414-417.

Maeda K, Ono S, Tazuke Y, et al. Long-term outcomes of congenital tracheal stenosis treated by metallic airway stenting. J Pediatr Surg 2013; 48: 293-296.

Butler CR, Speggiorin S, Rijnberg FM, et al. Outcomes of slide tracheoplasty in 101 children: a 17-year single-center experience. J Thorac Cardiovasc Surg 2014; 147: 1783-1789.

Smith WK, Morrison G. Balloon dilatation following tracheal reconstruction for congenital microtrachea. Int J Pediatr Otorhinolaryngol 2004; 68: 1563-1566.

Fabila TS, Menghraj SJ. One lung ventilation strategies for infants and children undergoing video assisted thoracoscopic surgery. Indian J Anaesth 2013; 57: 339-344.

Bétrémieux P, Tréguier C, Pladys $\mathrm{P}$, et al. Tracheobronchography and balloon dilatation in acquired neonatal tracheal stenosis. Arch Dis Child Fetal Neonatal Ed 1995; 72: F3-F7.

Watson G, Bhalla RK, Rothera MP. Relapsing diffuse idiopathic tracheal stenosis in a child: dilemmas in management. Int J Pediatr Otorhinolaryngol Extra 2006; 1: 261-266.

Wood JW, Thornton B, Brown CS, et al. Traumatic tracheal injury in children: a case series supporting conservative management. Int J Pediatr Otorhinolaryngol 2015; 79: 716-720.

Choong CK, Sweet SC, Zoole JB, et al. Bronchial airway anastomotic complications after pediatric lung transplantation: incidence, cause, management, and outcome. J Thorac Cardiovasc Surg 2006; 131: $198-203$.

Wong JS, Ng CS, Lee TW, et al. Bronchoscopic management of airway obstruction in pediatric endobronchial tuberculosis. Can Respir J 2006; 13: 219-221.

Hoff SR, Chang KW. The proximal bronchoplasty retrieval technique for removal of embedded distal airway foreign bodies. Int J Pediatr Otorhinolaryngol 2014; 78: 148-151.

Thornton CS, Yunker WK. Rigid bronchoscopy and balloon dilation for removal of aspirated thumbtacks: case series and literature review. Int J Pediatr Otorhinolaryngol 2015; 79: 1541-1543.

Ono S, Maeda K, Baba K, et al. Balloon tracheoplasty as init
congenital tracheal stenosis. Pediatr Surg Int 2014; 30: 957-960.

Tsui KY, Yu HR, Hwang KP, et al. When parents opted not to perform surgery for a long-segment congenital tracheal stenosis child: flexible bronchoscopic balloon tracheoplasty as the primary treatment. Eur J Cardiothorac Surg 2009; 36: 219-221.

16 Hathorn C, Armitage N, Wensley D, et al. Bronchial balloon occlusion in children with complex pulmonary air leaks. Arch Dis Child 2013; 98: 136-140.

Donato L, Tran TMH, Mihailidou E. Interventional bronchoscopy. In: Priftis KN, Anthracopoulos MB, Eber E et al., eds. Paediatric Bronchoscopy. Progress in Respiratory Research. Basel, Karger, 2010; pp. 64-74.

Sjogren PP, Sidman JD. Use of the carbon dioxide laser for tracheobronchial lesions in children. JAMA Otolaryngol Head Neck Surg 2013; 139: 231-235.

Sharp HR, Hartley BE. KTP laser treatment of suprastomal obstruction prior to decannulation in paediatric tracheostomy. Int J Pediatr Otorhinolaryngol 2002; 66: 125-130.

Int J Pediatr Otorhinolaryngol 2004; 68: 1423-1428.

Bhatnagar V, Lal R, Sriniwas M, et al. Endoscopic treatment of tracheoesophageal fistula using electrocautery and the Nd:YAG laser. J Pediatr Surg 1999; 34: 464-467.

Rahbar R, Chen JL, Rosen RL, et al. Endoscopic repair of laryngeal cleft type I and type II: when and why? Laryngoscope 2009; 119: 1797-1802. 
Baring DE, Ansari S, Clement WA, et al. Residual tracheal pouch after repair of tracheoesophageal fistula: endoscopic KTP laser treatment. J Pediatr Surg 2010; 45: 1040-1043.

Cholewa D, Waldschmidt J. Laser treatment of hemangiomas of the larynx and trachea. Lasers Surg Med 1998; 23: 221-232.

Bumber Z, Julrina M, Manojlović S, et al. Inflammatory pseudotumor of the trachea. J Pediatr Surg 2001; 36: 631-634.

Breen DP, Dubus JC, Chetaille B, et al. A rare cause of endobronchial tumour in children: the role of interventional bronchoscopy in the diagnosis and treatment of tumours while preserving lung function. Respiration 2008; 76: 444-448.

Rameau A, Zur KB. KTP laser ablation of extensive tracheal hemangiomas. Int J Pediatr Otorhinolaryngol 2011; 75: $1200-1203$.

Derkay CS, Wiatrak B. Recurrent respiratory papillomatosis: a review. Laryngoscope 2008; 118: 1236-1247.

Serio P, Fainardi V, Leone R, et al. Tracheobronchial obstruction: follow-up study of 100 children treated with airway stenting. Eur J Cardiothorac Surg 2014; 45: e100-e109.

Fayon M, Donato L, de Blic J, et al. French experience of silicone tracheobronchial stenting in children. Pediatr Pulmonol 2005; 39: 21-27.

Nicolai T. Airway stents in children. Pediatr Pulmonol 2008; 43: 330-344.

Antón-Pacheco JL, Luna C, García E, et al. Initial experience with a new biodegradable airway stent in children is this the stent we were waiting for? Pediatr Pulmonol 2016; 51: 607-612.

Sztanó B, Kiss G, Márai K, et al. Biodegradable airway stents in infants - potential life-threatening pitfalls. Int Pediatr Otorhinolaryngol 2016; 91: 86-89.

Leung L, Chung $\mathrm{PH}$, Wong $\mathrm{KK}$, et al. Management of tracheobronchial obstruction in infants using metallic stents: long-term outcome. Pediatr Surg Int 2015; 31: 249-254.

Xu X, Ding H, Liu X, et al. Emergency management for congenital tracheal stenosis with endoluminal stenting in pediatric intensive care units. Ther Adv Respir Dis 2016; 10: 310-317.

Antón-Pacheco JL, Cabezalí D, Tejedor R, et al. The role of airway stenting in pediatric tracheobronchial obstruction. Eur J Cardiothorac Surg 2008; 33: 1069-1075.

Reiter K, Schön C, Ensenauer R, et al. Tracheobronchial stents in mucopolysaccharidosis. Int J Pediatr Otorhinolaryngol 2016; 83: 187-192.

Siegel B, Bent JP, Ward RF. Endotracheal nitinol stents: lessons from the learning curve. Otolaryngol Head Neck Surg 2013; 148: 671-677.

Lund ME, Force S. Airway stenting for patients with benign airway disease and the Food and Drug Administration advisory: a call for restraint. Chest 2007; 132: 1107-1108.

Pasquale K, Wiatrak B, Woolley A, et al. Microdebrider versus $\mathrm{CO}_{2}$ laser removal of recurrent respiratory papillomas: a prospective analysis. Laryngoscope 2003; 113: 139-143.

Rees CJ, Tridico TI, Kirse DJ. Expanding applications for the microdebrider in pediatric endoscopic airway surgery. Otolaryngol Head Neck Surg 2005; 133: 509-513.

Yellon RF. Totally obstructing tracheotomy-associated suprastomal granulation tissue. Int J Pediatr Otorhinolaryngol 2000; 53: 49-55.

Wang H, Zhang J, Li D, et al. Efficacy of bronchoscopic therapies for bronchial mucoepidermoid carcinoma in children: results from six patients. Tumori 2015; 101: 52-56.

zgül MA, Toru Ü, Acat M, et al. A rare tumor of trachea: inflammatory myofibroblastic tumor diagnosis and endoscopic treatment. Respir Med Case Rep 2014; 13: 57-60.

Peng YY, Soong WJ, Lee YS, et al. Flexible bronchoscopy as a valuable diagnostic and therapeutic tool in pediatric intensive care patients: a report on 5 years of experience. Pediatr Pulmonol 2011; 46: 1031-1037.

Muhlebach MS, Shaffer CB, Georges L, et al. Bronchoscopy and airway management in patients with mucopolysaccharidoses (MPS). Pediatr Pulmonol 2013; 48: 601-607.

Field-Ridley A, Sethi V, Murthi S, et al. Utility of flexible fiberoptic bronchoscopy for critically ill pediatric patients: a systematic review. World J Crit Care Med 2015; 4: 77-88.

Fujii M, Tachibana K, Takeuchi M, et al. Perioperative management of 19 infants undergoing glossopexy (tongue-lip adhesion) procedure: a retrospective study. Paediatr Anaesth 2015; 25: 829-833.

Varghese E, Nagaraj R, Shwethapriya R. Comparison of oral fiberoptic intubation via a modified Guedel airway or a laryngeal mask airway in infants and children. J Anaesthesiol Clin Pharmacol 2013; 29: 52-55.

Choudhry DK, Brenn BR, Lutwin-Kawalec M, et al. Effect of $90^{\circ}$ counterclockwise rotation of the endotracheal tube on its advancement through the larynx during nasal fiberoptic intubation in children: a randomized and blinded study. Paediatr Anaesth 2016; 26: 378-383.

Meier JD, Sulman CG, Almond PS, et al. Endoscopic management of recurrent congenital tracheoesophageal fistula: a review of techniques and results. Int J Pediatr Otorhinolaryngol 2007; 71: 691-697.

Nardo GD, Oliva S, Barbato M, et al. Video: argon
tracheoesophageal fistula. Surg Endosc 2012; 26: 2678-2680.

Aworanti O, Awadalla S. Management of recurrent tracheoesophageal fistulas: a systematic review. Eur J Pediatr Surg 2014; 24: 365-375.

Lelonge Y, Varlet F, Varela P, et al. Chemocauterization with trichloroacetic acid in congenital and recurrent tracheoesophageal fistula: a minimally invasive treatment. Surg Endosc 2016; 30: 1662-1666.

Tzifa KT, Maxwell EL, Chait P, et al. Endoscopic treatment of congenital H-Type and recurrent tracheoesophageal fistula with electrocautery and histoacryl glue. Int J Pediatr Otorhinolaryngol 2006; 70: 925-930.

6 Daniel SJ, Smith MM. Tracheoesophageal fistula: open versus endoscopic repair. Curr Opin Otolaryngol Head Neck Surg 2016; 24: 510-515.

Goussard P, Gie RP, Kling S, et al. Fibrin glue closure of persistent bronchopleural fistula following pneumonectomy for post-tuberculosis bronchiectasis. Pediatr Pulmonol 2008; 43: 721-725.

Saleemi MS, McLaren C, Sharma BK, et al. Bronchopleural fistula in a newborn undergoing ECMO-transbronchial closure. J Perinatol 2013; 33: 659-660. 
York EL, Lewall DB, Hirji M. Endoscopic diagnosis and treatment of postoperative bronchopleural fistula. Chest 1990; 97: 1390-1392.

160 Sarkar P, Chandak T, Shah R, et al. Diagnosis and management bronchopleural fistula. Indian J Chest Dis Allied Sci 2010; 52: 97-104.

161 Krause MF, von Bismarck P, Oppermann HC, et al. Bronchoscopic surfactant administration in pediatric patients with persistent lobar atelectasis. Respiration 2008; 75: 100-104.

162 Shah PL, Scott SF, Hodson ME. Lobar atelectasis in cystic fibrosis and treatment with recombinant human DNase I. Respir Med 1994; 88: 313-315.

163 Hendriks T, de Hoog M, Lequin MH, et al. DNase and atelectasis in non-cystic fibrosis pediatric patients. Crit Care 2005; 9: R351-R356.

164 MacKinnon R, Wheeler KI, Sokol J. Endotracheal DNase for atelectasis in ventilated neonates. J Perinatol 2011; 31: 799-801.

165 Gibb E, Blount R, Lewis $\mathrm{N}$, et al. Management of plastic bronchitis with topical tissue-type plasminogen activator. Pediatrics 2012; 130: e446-e450.

166 Parent JJ, Darragh RK, Gossett JG, et al. Strategies to prevent cast formation in patients with plastic bronchitis undergoing heart transplantation. Pediatr Cardiol 2017; 38: 1077-1079.

167 Kamin W, Klär-Hlawatsch B, Truebel H. Easy removal of a large mucus plug with a flexible paediatric bronchoscope after administration of rhDNase (Pulmozyme). Klin Padiatr 2006; 218: 88-91.

168 Lis G, Cichocka-Jarosz E, Jedynak-Wasowicz U, et al. Add-on treatment with nebulized hypertonic saline in a child with plastic bronchitis after the Glenn procedure. J Bras Pneumol 2014; 40: 82-85.

169 Sidman JD, Wheeler WB, Cabalka AK, et al. Management of acute pulmonary hemorrhage in children. Laryngoscope 2001; 111: 33-35.

170 Babycenter Community. Bronchoscopy. Date last accessed: 9 April 2017. Date last updated: 21 April 2011.

171 Adramerina A, Xatzigeorgiou S, Spanou C, et al. How parents' lack of awareness could be associated with foreign body aspiration in children. Pediatr Emerg Care 2016; 32: 98-100.

172 Foltran F, Ballali S, Rodriguez H, et al. Inhaled foreign bodies in children: a global perspective on their epidemiological, clinical, and preventive aspects. Pediatr Pulmonol 2013; 48: 344-351.

173 Moretti C, Foltran F. Prevention and early recognition: the role of family pediatrician. Int J Pediatr Otorhinolaryngol 2012; 76: Suppl. 1, S39-S41.

174 Iversen RH, Klug TE. Need for more clear parental recommendations regarding foreign body aspiration in children. Dan Med J 2012; 59: A4498.

175 de Koning T, Foltran F, Gregori D. Fostering design for avoiding small parts in commonly used objects. Int $J$ Pediatr Otorhinolaryngol 2012; 76: Suppl. 1, S57-S60.

176 Choroomi S, Curotta J. Foreign body aspiration and language spoken at home: 10-year review. J Laryngol Otol 2011; 125: 719-723.

177 Paul SP, Sanjeevaiah MK, Routley C, et al. Ingestion or aspiration of foreign bodies by children. Emerg Nurse 2013; 21: 32-36. 